\title{
On the Milling Strategy in Machining Curved Surfaces Based on Minimum Stress Concentration by a 3-axis Machining Center
}

\section{Hang Li}

Qilu University of Technology

\section{Peirong Zhang}

Qilu University of Technology

Guosheng Su ( $\sim$ suguosheng@sina.com )

Qilu University of Technology

Jin Du

Qilu University of Technology

\section{Chonghai Xu}

Qilu University of Technology

\section{Research Article}

Keywords: Interpolation lines, Surfaces topography, Stress concentration, Surfaces with variable curvature

Posted Date: August 31st, 2021

DOI: https://doi.org/10.21203/rs.3.rs-837727/v1

License: (c) (i) This work is licensed under a Creative Commons Attribution 4.0 International License. Read Full License

Version of Record: A version of this preprint was published at The International Journal of Advanced Manufacturing Technology on January 26th, 2022. See the published version at https://doi.org/10.1007/s00170-022-08688-1. 
On the milling strategy in machining curved surfaces based on minimum stress concentration by a

\section{3-axis machining center}

Hang Li, Peirong Zhang, Guosheng Su*, Jin Du, Chonghai Xu

ABSTRACT

3-axis computer numerical control machining centers are used in machining due to their simple operation. When machining curved surfaces, the 3 -axis CNC machining centers use interpolation lines segment to fit the curved surfaces. The quality of the machined surface is affected by the length of the interpolation line segment. Sharp corners are formed at the junction of straight segments. The appearance of sharp corners will lead to increased stress concentration. To study the relationship between surface quality and interpolation straight line in surface processing, this paper establishes the mathematical model of surface topography in 3-axis ball-end milling curved surfaces based on the acceleration and deceleration control. Based on the surface topography model, the surfaces stress concentration factor analysis is carried out in machining curved surfaces with variable curvatures with different lengths of interpolation lines. The results show that when the length of interpolation lines and the radius of curvature are kept constant, the stress concentration factor decreases with the increase of the central angle. When the length of the interpolation lines and the central angle are kept constant, the stress concentration factor decreases with the increase of the radius of curvature. When the radius of curvature and the central angle are kept constant, the stress concentration factor increases as the length of the interpolation lines increases. A method of selecting the length of interpolation lines based on the surface's stress concentration is proposed. Through the optimization of the tool path, the quality of the machined surfaces can be improved.

Keywords Interpolation lines; Surfaces topography; Stress concentration; Surfaces with variable curvature

\section{Instruction}

To reduce wind resistance, more and more curved surfaces conforming to fluid mechanics have been designed. When machining curved surfaces, ball-end milling is often used. The 3-axis CNC machining center uses lines segment to fit the curved surfaces. Too large interpolation line length will cause the form tolerances not to meet the requirements. Too small interpolation straight line length will cause frequent acceleration and deceleration of the $\mathrm{CNC}$ machining center, and will also cause a reduction in surface quality.

Scholars at home and abroad have optimized some cutting parameters by establishing surface

\footnotetext{
$\triangle$ Guosheng Su

sgs@qlu.edu.cn; suguosheng@sina.com

${ }^{1}$ Qilu University of Technology (Shandong Academy

of Sciences), School of Mechanical \& Automotive

Engineering, Jinan 250306, China

${ }^{2}$ Shandong Institute of Mechanical Design and

Research, Jinan 250031, China
}

models for turning or milling. Rao and Rao. [1] established the model of tooth track and machining geometry in the process of surface edge milling. Real tooth lines are considered in the geometric modeling of the surface milling process. The mathematical expressions of feed, tooth entry and exit Angle, undeformed chip thickness, and surfaces error along the tool contact path were derived, and the effects of workpiece curvature on these variables were studied. Wei et all. [2] discretized the entire cutting process into a series of small lines milling along the tool path. A mathematical model is established for the process of segmented cutting. Zhang and Liu. [3] established a turning surfaces model of Wiper inserts. Mohammad and Mohammad. [4] proposed an analytical model for calculating the tool-workpiece meshing boundary during the finish milling of the curved surfaces ball end. Li et all. [5] proposed an improved Z-MAP algorithm based on the time-step method 
to simulate the surface topography of parts after ball-end milling.

In addition, some scholars have considered factors such as vibration and machining strategy based on cutting to optimize and improve the model. Dhokia et al. [6] established a prediction model for the surface morphology of ball-end milled polypropylene. It can make a certain prediction of surface roughness. But this model is only suitable for soft materials such as polypropylene. Quniast et al. [7] proposed a method to characterize the three-dimensional topography of complex ball milling surfaces and established a 5-axis ball milling model. The results show that the inclination of the tool has a significant effect on the surface quality. This model has only been verified in flat ball milling. Vyboishchik. [8] studied the three strategies of "along the track", "cross-track" and "angle to track" in rough machining, and proposed a model for the combination of topological trajectories of machining surfaces. This model can predict cutting force and obtain surface accuracy. Xu et all. [9] proposed a scanning method for surface topography modeling of ball-end milling. On this basis, an interpolation-based method is given to accurately calculate the height of the cusp of any point on the workpiece. Vu et all. [10] took the free-form surface's three-axis end milling as the research object and optimized the tool path design. A method of generating different tool paths in different areas of the machined surfaces by using a toroidal milling cutter is proposed. Lotfi et al. [11] established a multi-axis ball-end milling surface topography model based on the machining tool trajectory and the real trajectory of the cutting edge relative to the workpiece and the tool-to-tool meshing area. The results show that the orientation of the tool plays a key role in the surface topography. This model does not consider the two influencing factors of tool wear and tool vibration. Arizmendi and Jiménez. [12] proposed a kinematics method for predicting the three-dimensional shape of the milling surfaces in the milling process of face milling cutters of different geometric shapes considering the axial and radial runout. Through the simulation of the three-dimensional surface topography, the peak and valley changes of the milling cutter can be predicted during the cutting process. Torta et all. [13] established a three-dimensional surface shape prediction model for the milling process. The model is suitable for real cutting vibration and a specific program has been developed to measure the actual position and shape of each cutting edge to achieve accurate surface geometry reproduction. Cai et al. [14] established a surface topography prediction model for external milling. This model adds factors such as tool static deflection and chatter. It can accurately predict the surface topography of flat-end milling cutter plane milling. Most of them are turning surfaces topography models and milling plane surfaces topography models, and there are few surface topography models that fit curved surfaces through equidistant lines interpolation. In this paper, the tool trajectory of equidistant lines interpolation to fit the curved surfaces is established, and the acceleration and deceleration of the machine tool are considered, and the surface's topography coordinates are obtained by retaining the minimum $\mathrm{Z}$ coordinate to form the machined surfaces.

The processed surfaces are generally characterized by roughness and stress concentration factor. Roughness reflects the quality of the surfaces, the stress concentration factor can reflect the defects of the surfaces, and the stress concentration on the surfaces will provide a more reliable estimate of the fatigue of the parts [15]. Urbikain and Lacalle. [16] proposed a shape prediction method based on time-domain model for circular milling cutter when milling inclined plane. Provides tool integrity characterization and surfaces roughness prediction. This can estimate the roughness of any combination of geometry and cutting parameters. Zeng et all. [17] considered the 
non-uniformity and instantaneous characteristics of stress distribution along the cutting edge during milling. The notch wears depth prediction model considering the influence of stress concentration is established. Yang et all. [18] used the regression analysis method to process and analyze the data, and established a prediction model of surface roughness and work hardening. It provides a theoretical basis for improving the cutting performance and surface processing quality of cemented carbide tools. Zhou and Yang. [19] established an analysis model for the residual stress generated by the milling of complex curved surfaces. The analytical model is used to predict the temperature field of the workpiece during the milling process. Li et all. [20] based on the characteristics of high-speed milling ball heads and metal cutting theory, revealed the mechanism of surface deformation of high-speed milling ball heads. Using the deformation theory, the non-destructive measurement method is used to measure the surface's residual stress of high-speed ball-end milling. The polynomial fitting equation of the surface's residual stress accumulation coefficient and the analysis and prediction model of the surface's residual stress concentration under high-speed milling conditions are established. Jaime Tupiassú Pinho et al. [21] mentioned that notches can cause local stress concentration effects and affect various failure mechanisms. Tabriz and Barrans. [22] analyzed the stress concentration formed by the sharp point of the ball end milling cutter. Studies have shown that as the depth of the cusp increases, the stress concentration factor increases significantly; the smaller the radius of curvature, the higher the stress concentration factor. Felhőa et all. [23] proposed a new method to determine the expected value of surface roughness parameters during face milling. This method can be used to analyze the theoretical morphology of grinding surfaces and to determine the theoretical roughness of any point on the surfaces. Chen et al.
[24] studied the effect of the UVHM process on the residual compressive stress of the hole and made the surface residual compressive stress by 63.5\%. This paper uses ANSYS to analyze the surface topography model. According to actual working conditions, constraints and pressure are applied to obtain the maximum stress and average stress of the surface's topography, and then the stress concentration factor is obtained.

To mill better curved surfaces with a 3 -axis CNC machining center. In this paper, a surfaces topography model of ball-end milling surface based on acceleration and deceleration control is established. The tool path of the curved surfaces is formed by fitting straight line segments. And through the joint simulation of MATLAB and ANSYS, the relationship between the radius of curvature, the machining error, the length of interpolation lines, and the stress concentration factor are obtained. It is proposed to optimize the length of the interpolation lines through the curvature, the machining error range, and the stress concentration coefficient, and then to optimize the tool path.

2. Theoretical modeling of surfaces topography model of ball-end milling curved surfaces

\subsection{The surfaces topography model of the} ball-end milling surfaces is established

\subsubsection{The coordinate system is established}

In 3-axis CNC machining, the spindle of the machine tool moves in the $Z$ direction, and the worktable moves in the $X$ and $Y$ directions. The workpiece is fixed so that the relative movement between the tool and the workpiece is processed into a new machining surface. Assuming that the workpiece is stationary. Relative to the workpiece, the tool feeds in the $X 、 Y$ and $Z$ directions. The coordinate system of the workpiece-tool is established, and the axis directions of the two coordinate systems are the same. As shown in Fig 1. $O-X Y Z$ represents the workpiece coordinate system. $O^{\prime}-X^{\prime} Y^{\prime} Z^{\prime}$ represents the tool coordinate system. 


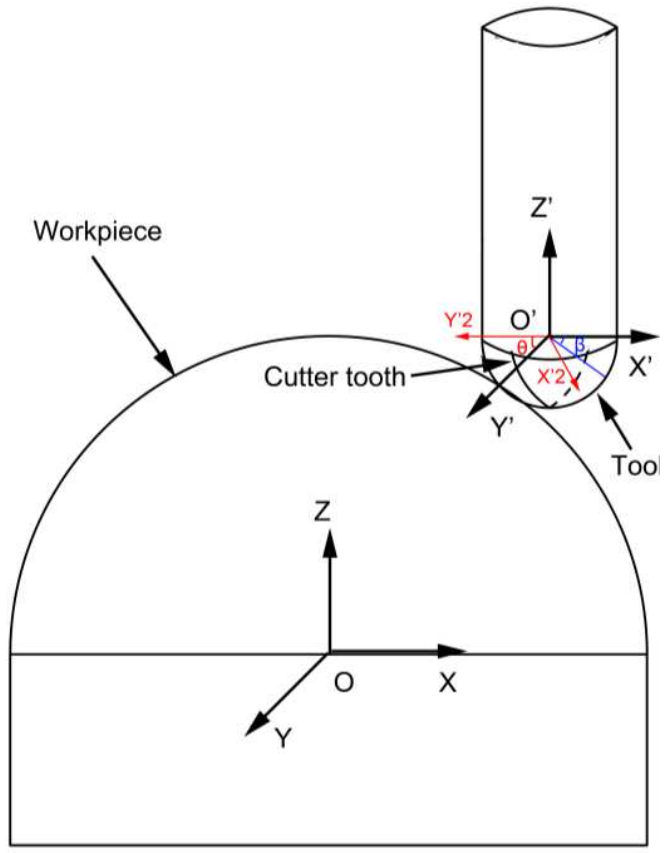

Fig. 1. The coordinate system is established

\subsubsection{Coordinate transformation matrix}

The coordinate transformation matrix can transform the coordinates of one coordinate system into the coordinates of another coordinate system. The starting phase angle of the tool coordinate system and the workpiece coordinate system are the same. When the tool rotates, the cosine of the angle between the $X$ 'axis in the tool coordinate system and the $X$ axis in the workpiece coordinate system changes with time. Assume that the angle between the $X^{\prime}$-axis and the $X$-axis is $\theta$. The coordinate transformation matrix can be changed to:

$$
\left[\begin{array}{l}
X \\
Y \\
Z \\
t
\end{array}\right]=\left[\begin{array}{cccc}
\cos \theta & -\sin \theta & 0 & X_{0} \\
\sin \theta & \cos \theta & 0 & Y_{0} \\
0 & 0 & 1 & Z_{0} \\
0 & 0 & 0 & 1
\end{array}\right]\left[\begin{array}{c}
X^{\prime} \\
Y^{\prime} \\
Z^{\prime} \\
1
\end{array}\right]
$$

Among them $\theta=\omega t=2 \pi n t / 60=\pi n t / 30 . n$ is the speed of the CNC machining center. $\left(X_{0}, Y_{0}, Z_{0}\right)$ are the coordinates of the coordinate origin of the tool coordinate system in the workpiece coordinate system. $\left(X^{\prime}, Y^{\prime}, Z^{\prime}\right)$ are the coordinates of any point in the tool coordinate system.

\subsubsection{The motion path equation of the tool sphere center in the workpiece coordinate system}

When milling a curved surface along the interpolation lines, the motion path equation of the center point of the tool is as follows:

$$
\left\{\begin{array}{l}
X_{0}=V_{f}\left(\left(t_{1}-0\right) / \sqrt{1+K_{1}^{2}}+\mathrm{L}+\left(t_{i}-t_{i-1}\right) / \sqrt{1+K_{i}^{2}}\right) / 60-(R+r), t_{i-1} \leq t \leq t_{i} \\
Y_{0}=0,0.5,1 \mathrm{~L} 10 \\
Z_{0}=K_{\mathrm{i}}\left(X_{0}-\left(X_{i}+R \cos \alpha_{i}\right)\right)+Z_{i}+R \sin \alpha_{i}-a_{p}
\end{array}\right.
$$

Where $K_{i}$ is the slope of each interpolation line

$K_{i}=\frac{\left(Z_{i+1}+r \sin \alpha_{i+1}-\left(Z_{i}+r \sin \alpha_{i}\right)\right)}{\left(X_{i+1}+r \sin \alpha_{i+1}-\left(X_{i}+r \cos \alpha_{i}\right)\right)}$ $\cos \alpha_{i}=X_{i} / R, \sin \alpha_{i}=Z_{i} / R, X_{i}$ and $Z_{i}$ Satisfy the formula $X_{i}^{2}+Z_{i}^{2}=R^{2} \quad . \quad K_{i}=\tan \eta_{i}=\sin \eta_{i} / \cos \eta_{i}$, According to the triangulation relationship. $\cos \eta_{i}=1 / \sqrt{1+\left(\tan \eta_{i}\right)^{2}}=1 / \sqrt{1+K_{i}^{2}}$ $t_{i}$ represents the total time spent processing to $X_{i}$.
$V_{f}$ represents the feed rate. $R$ represents the radius of curvature of the surfaces. $r$ represents the radius of the ball end mill. $a_{p}$ represents the depth of cut. $\alpha_{i}$ is the angle between the lines formed by the endpoint of the interpolation lines and the center of the circle of curvature and the positive $X$ half axis. $\mathrm{t}$ represents discrete processing time. When machining curved surfaces, the processed surfaces is divided into small areas. $\left[X_{i}, X_{i+1}\right]$ is the interval range. As shown in Fig 2. To avoid the tip of the tool from participating in the cutting, it is necessary to ensure that the cutting is tangent to the curved 
surfaces. So $\left[X_{i}+r \cos \alpha_{i}, X_{i+1}+r \cos \alpha_{i+1}\right]$ is the interval range of the center point of the tool. First, calculate the length of $X$ based on time. Then determine which range of $X$ is in. Finally, find the coordinate of $Z$ according to the linear equation.

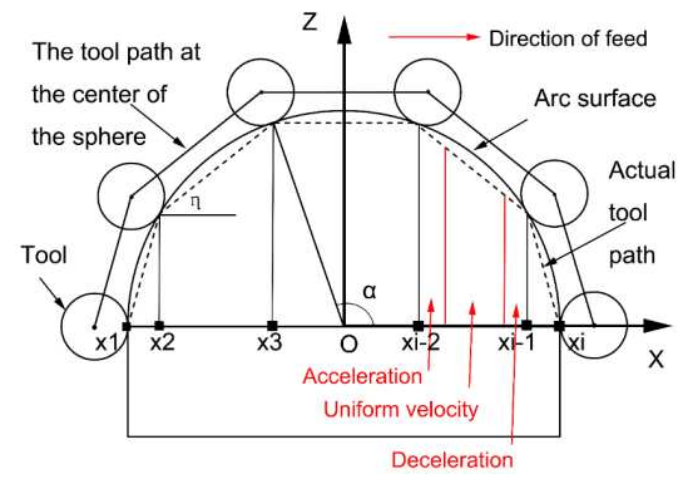

Fig. 2. Divide the interval

In $\mathrm{CNC}$ machining center machining, the acceleration and deceleration of the CNC machining center is an unavoidable factor. T-type acceleration and deceleration control is a common acceleration and deceleration control method in the CNC machining center. It divides the movement process into three processes of acceleration-uniform speed-deceleration to ensure the consistency of acceleration. The length of an interpolated line is composed of three stages: acceleration-constant speed-deceleration.

As shown in Fig 3. Assuming that the feed rate in the deceleration phase is $1800 \mathrm{~mm} / \mathrm{min}$, the feed rate in the constant speed phase is $2000 \mathrm{~mm} / \mathrm{min}$, and the time during the acceleration and deceleration phase is $0.05 \mathrm{~s}$. According to the speed-displacement formula, the acceleration is $200 / 3 \mathrm{~mm} / \mathrm{s}$, and the length of acceleration (deceleration) is $19 / 12 \mathrm{~mm}$

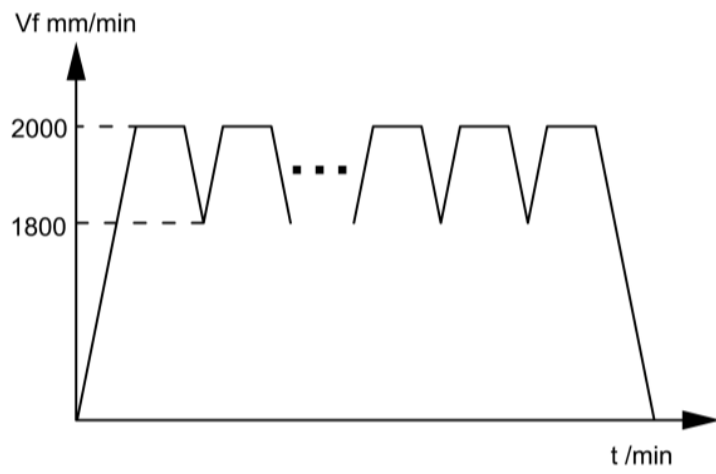

Fig. 3. T type acceleration and deceleration

When considering the acceleration and deceleration of each interpolation line. The interval of the acceleration phase is $\left[X_{\mathrm{i}}+r \cos \alpha_{\mathrm{i}}, X_{\mathrm{i}}+r \cos \alpha_{\mathrm{i}}+(19 / 12) \times \tan \eta_{\mathrm{i}}\right]$. The interval of the uniform speed stage is $\left[X_{\mathrm{i}}+r \cos \alpha_{\mathrm{i}}+\frac{19}{12} \tan \eta_{\mathrm{i}}, X_{\mathrm{i}+1}+r \cos \alpha_{\mathrm{i}+1}-\frac{19}{12} \tan \eta_{\mathrm{i}}\right]$. The interval of the deceleration phase is $\left[X_{i+1}+r \cos \alpha_{\mathrm{i}+1}-\frac{19}{12} \tan \eta_{\mathrm{i}}, X_{i+1}+r \cos \alpha_{\mathrm{i}+1}\right]$.

The number of judgment intervals is $3(i-1)$. As shown in fig 2 . Due to too much time change, the overall programming is more difficult. Capture a small area for simulation. The length of the adjacent interpolation lines is similar. In the intercepted part, the length and time of the interpolation lines in the middle are used for the length and time of each interpolation line. The idea of writing $X_{0}$ is shown in Fig 4. 


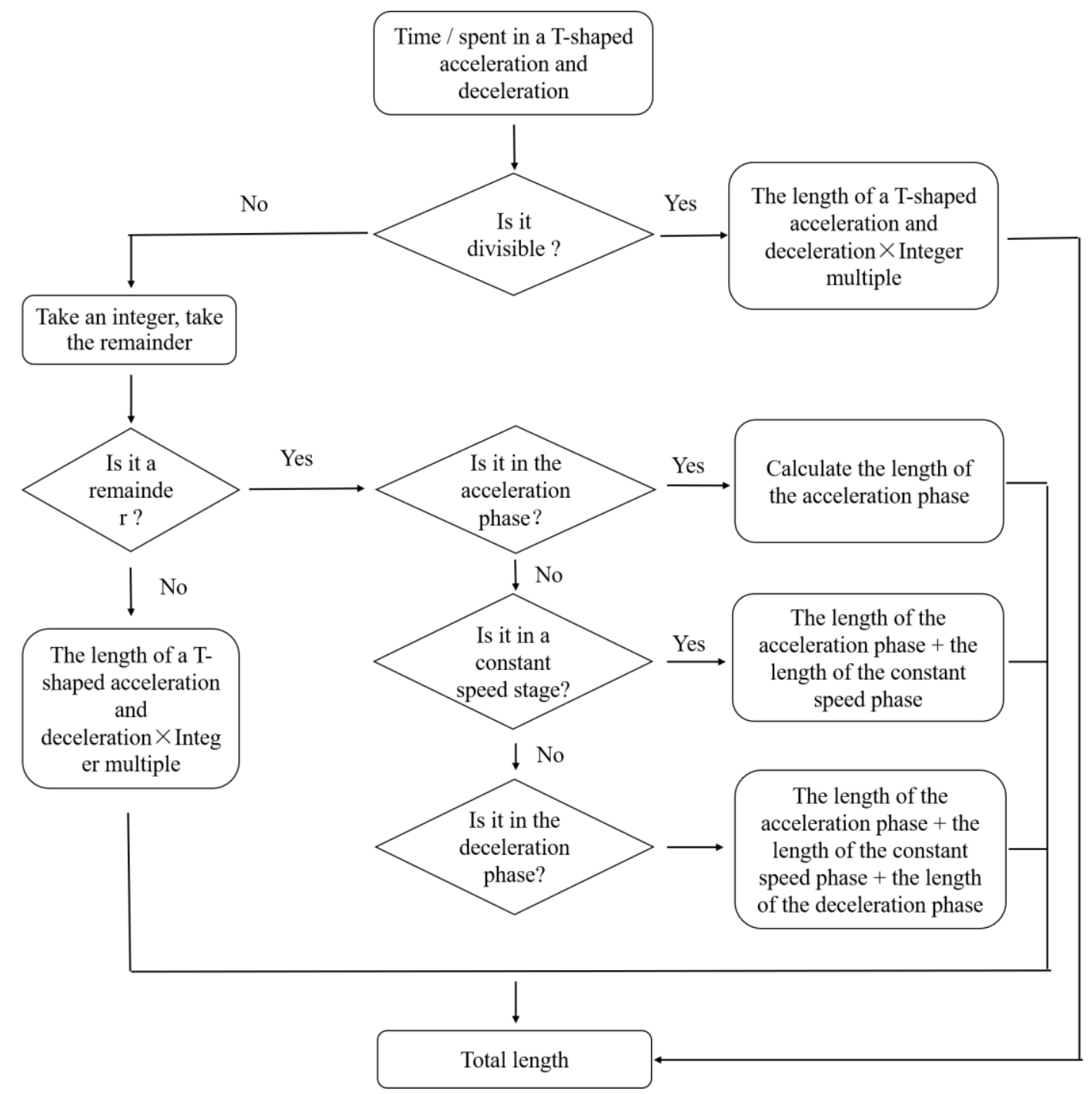

Fig. 4. Programming of acceleration and deceleration

In the case of acceleration and deceleration, edge are:

formula (2) can be changed to:

$\left\{\begin{array}{l}X_{0}=-L-r \times(l / R)+X_{00}+X_{000} \\ Y_{0}=0,0.5,1 \mathrm{~L} 10 \\ Z_{0}=K_{i}\left(X_{0}-\left(X_{i}+R \cos \alpha_{i}\right)\right)+Z_{i}+R \sin \alpha_{i}-e\end{array}\right.$

$L$ represents the coordinates of the starting point of cutting. $l$ represents the $X$ coordinate where the endpoint of the interpolation line is projected on the $x$-axis and is the farthest from the center. $X_{00}$ represents the length of an integer multiple of the interpolation lines. $X_{000}$ represents the length of the remaining interpolation lines.

\subsubsection{Coordinates of the cutting edge of the}

\section{tool}

In the tool coordinate system, the coordinates of any cutting point on the cutting

$$
\left\{\begin{array}{l}
X^{\prime}=r \cos \beta \\
Y^{\prime}=0 \\
Z^{\prime}=r \sin \beta
\end{array}\right.
$$

Finally, the coordinates of any cutting point at any time can be expressed by the formula (5).

$$
\left[\begin{array}{c}
X \\
Y \\
Z \\
t
\end{array}\right]=\left[\begin{array}{cccc}
\cos \theta & -\sin \theta & 0 & X_{0} \\
\sin \theta & \cos \theta & 0 & Y_{0} \\
0 & 0 & 1 & Z_{0} \\
0 & 0 & 0 & 1
\end{array}\right]\left[\begin{array}{c}
r \cos \beta \\
0 \\
r \sin \beta \\
1
\end{array}\right](5)
$$

2.2 Surfaces topography and stress concentration simulation

\subsubsection{Surfaces topography simulation}

Use MATLAB software as a tool to simulate surface appearance. First, create a cube model of 
the workpiece. The part model is discretized. Then establish the motion trajectory equation of the tool sphere center. Finally, compare the size of the cutting edge and the workpiece in the $\mathrm{Z}$ direction. Generate machined surfaces topography. The process is shown in Fig 5.

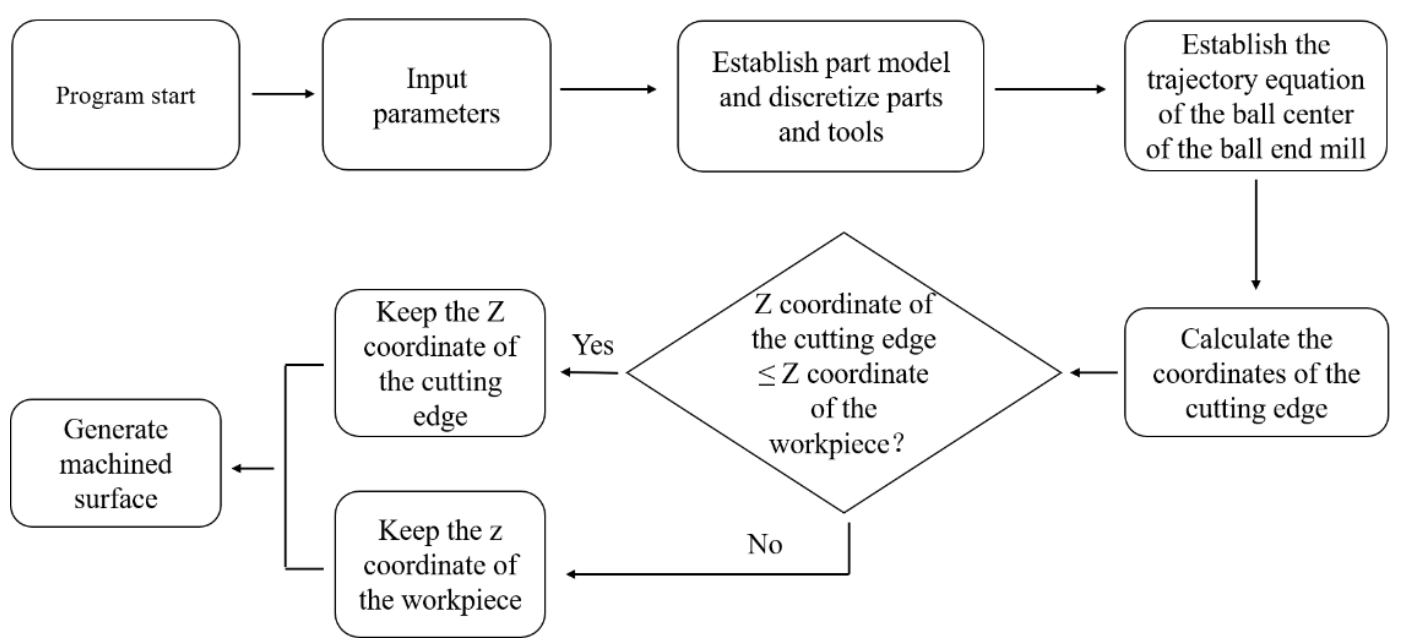

Fig. 5. Programming of surfaces topography

Fig. 6 shows the simulation of surfaces $1000 \mathrm{~mm}$, the central angle of $45.6^{\circ}$, and the topography taken under the radius of curvature of length of the interpolation lines of $10 \mathrm{~mm}$.
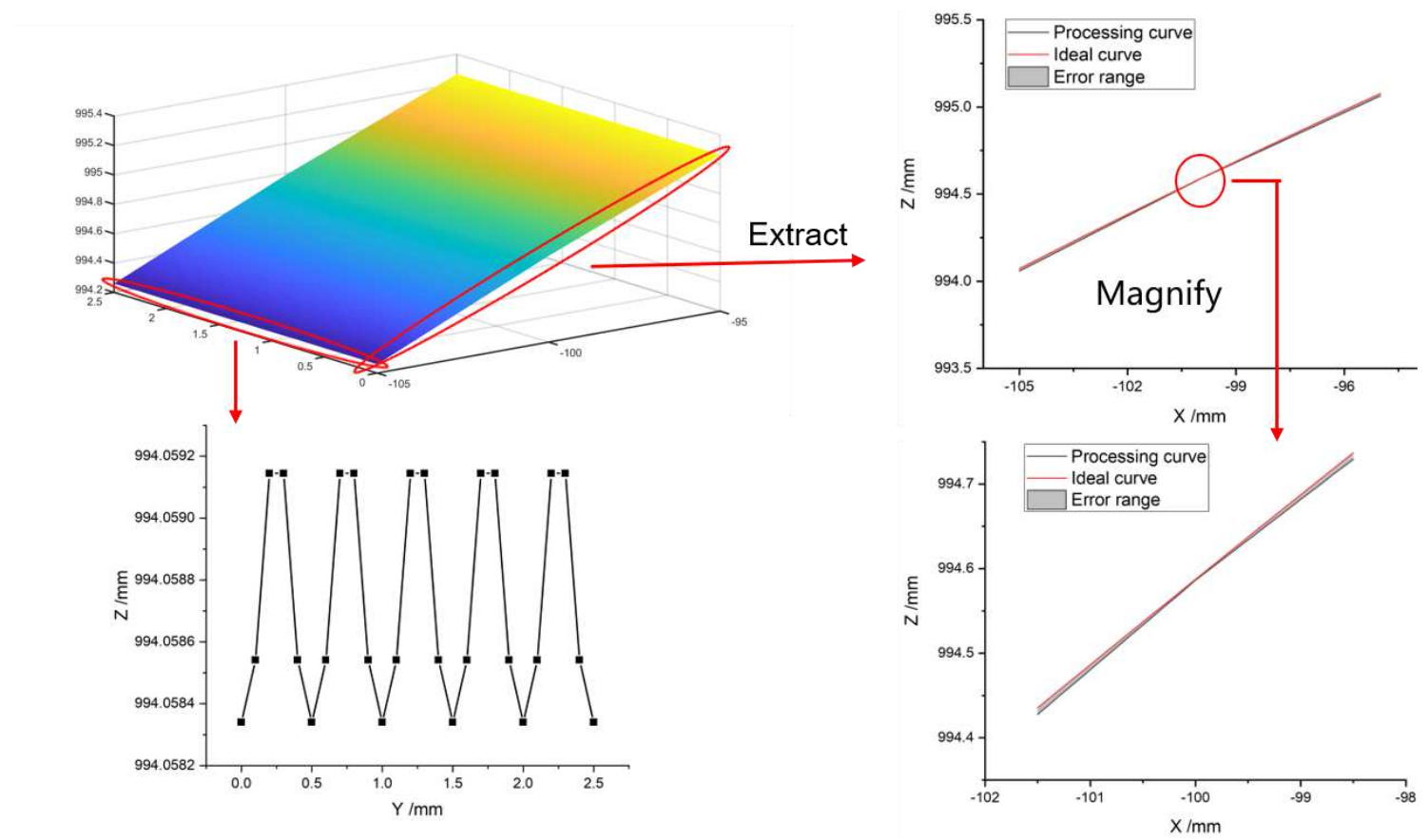

Fig. 6. Simulation of surface topography

\subsubsection{Stress concentration simulation}

The central angle of the selected area is $84.26^{\circ}(\operatorname{arc} \cos 0.1), \quad 72.54^{\circ}(\arccos 0.3), \quad 60^{\circ}(\operatorname{arc}$ $\cos 0.5), \quad 45.57^{\circ}(\operatorname{arc} \cos 0.7)$. As shown in Fig 7. 


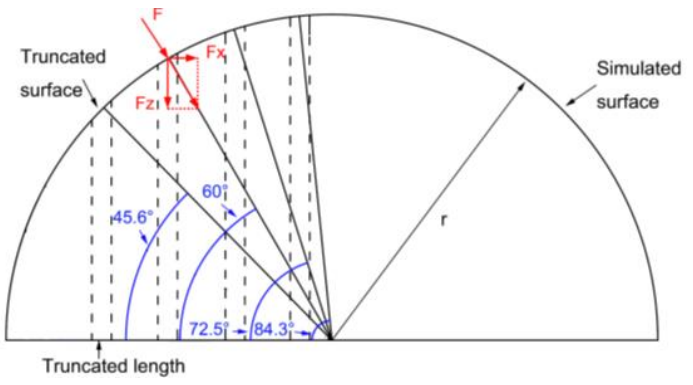

Fig. 7. Excerpted interval

In MATLAB, the coordinate points of the simulated surfaces are extracted. Use the command stream instructions in ANSYS to reconstruct the machined surfaces.

Import the machined surfaces model into the WORKBENCH, and then define the properties of the material. The defined material properties are shown in Table 1. Set the thickness of the surfaces to $0.1 \mathrm{~mm}$, and apply fixed constraints at both ends. Pressure is applied to the interpolated lines connection. The direction of the pressure is perpendicular to the tangent lines at the joint of the interpolation lines and points to the center of the curve.

Table 1 QT600 material properties

\begin{tabular}{ccc}
\hline Density $\mathrm{kg} / \mathrm{m}^{3}$ & Elastic Modulus & Poisson's ratio \\
\hline 7120 & $1.69 \mathrm{E}+11$ & 0.286 \\
\hline
\end{tabular}

Change the length of the interpolation lines, simulation parameters are shown in Tab 2. the size of the curvature, and the angle of the center angle for single factor simulation. The

Table 2 Simulation parameters

\begin{tabular}{ccccc}
\hline $\begin{array}{c}\text { The radius of } \\
\text { curvature } / \mathrm{mm}\end{array}$ & 1000 & 2000 & 3000 & 4000 \\
\hline $\begin{array}{c}\text { Central angle } \\
\text { The length of } \\
\text { interpolation } \\
\text { lines } / \mathrm{mm}\end{array}$ & 10 & $45.6^{\circ}, 60^{\circ}, 72.5^{\circ}, 84.3^{\circ}$ & \\
\hline
\end{tabular}

The length of the interpolation lines is under different curvatures is shown in Fig 8.

$10 \mathrm{~mm}$, the central angle is $45.6^{\circ}$, and the stress

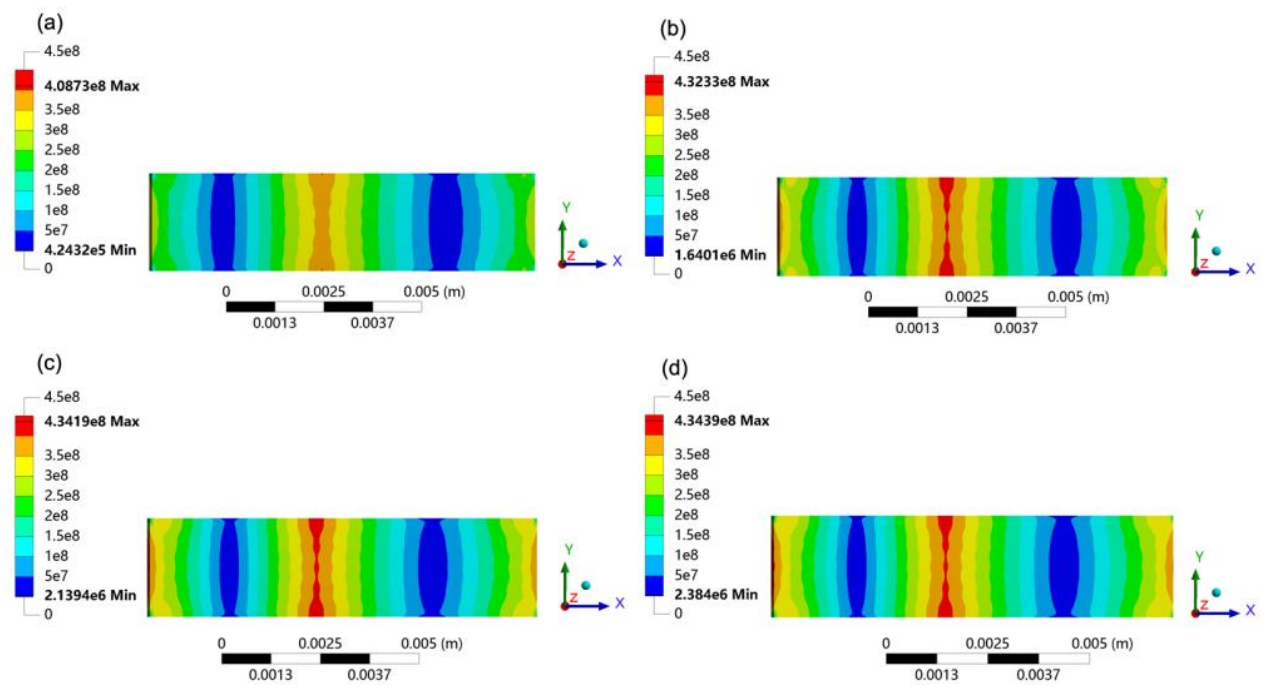

Fig. 8. The length of interpolation lines is $10 \mathrm{~mm}$, the central angle is $45.6^{\circ}$, and the stress simulation diagram under the different radius of curvature; (a) The radius of curvature is $1000 \mathrm{~mm}$ (b) The radius of curvature is $2000 \mathrm{~mm}$ (c) The radius of curvature is $3000 \mathrm{~mm}$ (d) The radius of curvature is $4000 \mathrm{~mm}$ 
The curvature is $3000 \mathrm{~mm}$, the central angle straight lines length is shown in Fig 9. is $45.6^{\circ}$, and the stress of different interpolation
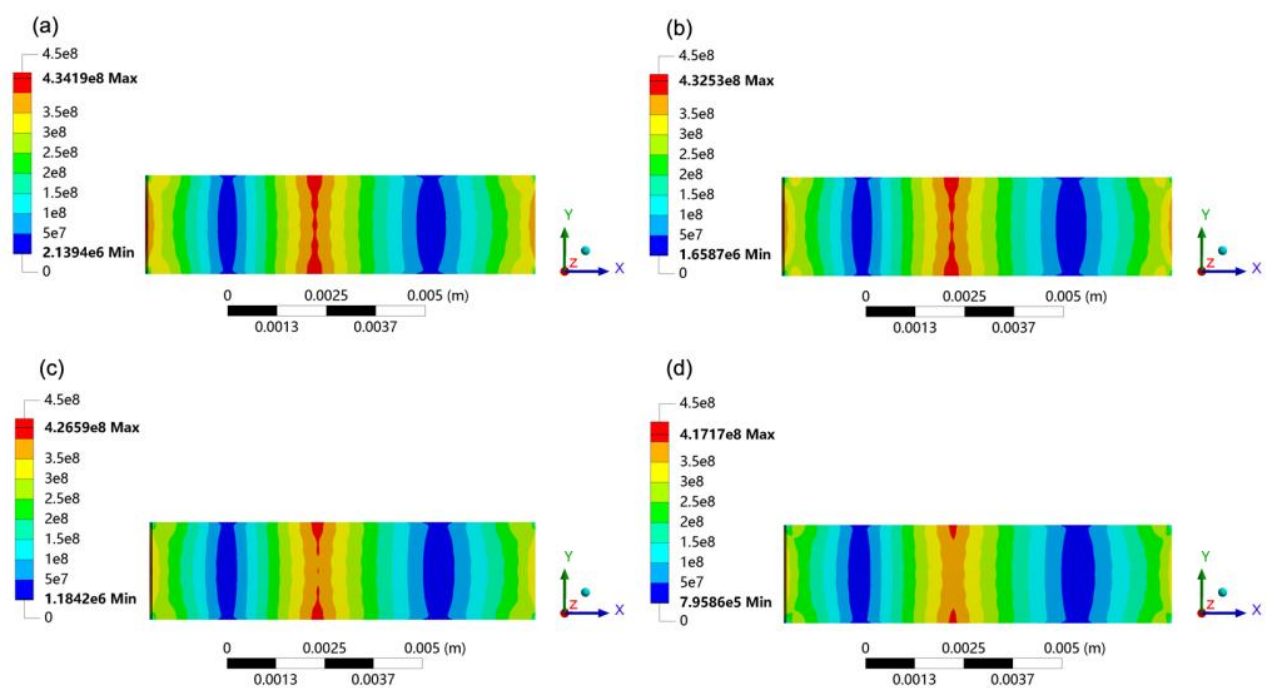

Fig. 9. The central angle is $45.6^{\circ}$, the radius of curvature is $3000 \mathrm{~mm}$, and the stress simulation diagrams of different interpolation straight lines lengths; (a) The length of interpolation lines is 10mm (b) The length of Interpolation lines is $15 \mathrm{~mm}$ (c) The length of Interpolation lines is $20 \mathrm{~mm}$ (d) The length of Interpolation lines is $25 \mathrm{~mm}$

\section{Results}

\subsection{Stress Simulation of curved surfaces with variable curvatures}

Solve the stress concentration factor according to the formula: $\mathrm{Kt}=\sigma_{1} / \sigma_{\mathrm{m}} . \sigma_{1}$ is the maximum stress, and $\sigma_{\mathrm{m}}$ is the average stress.

The length of the interpolation lines is $10 \mathrm{~mm}$, and the maximum stress and average stress under different central angles and curvatures are shown in Fig 10. The stress concentration factor is shown in Fig 11.

When the curvature is kept constant, the maximum stress decreases as the central angle increases. When the central angle and the length of the interpolation lines are kept constant, the maximum stress increases with the increase of radius of curvature. But when the central angle is large, the increasing trend of the maximum stress is not obvious. As shown in Fig 10. When the central angle and the length of the interpolation lines are kept constant, the stress concentration factor decreases with the increase of radius of curvature.

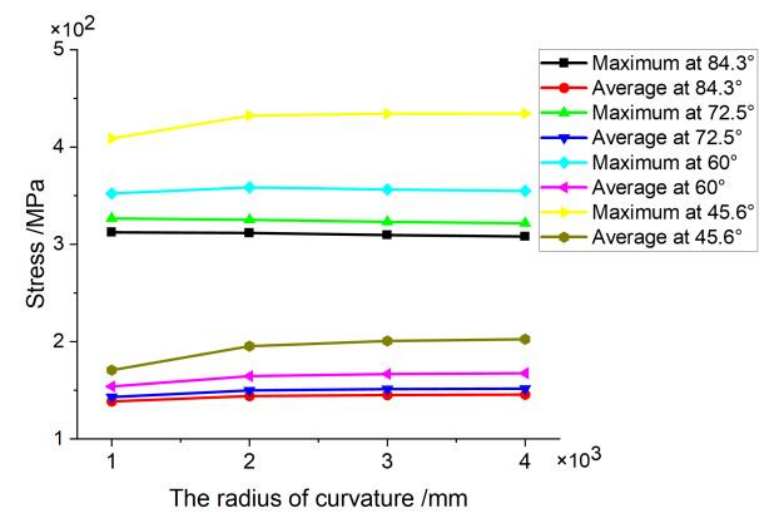

Fig. 10. Maximum stress and average stress for the different radius of curvature

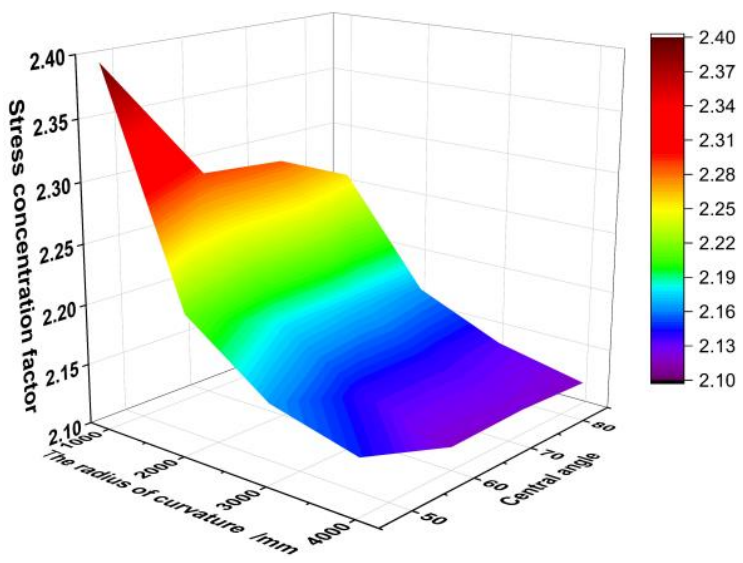

Fig. 11. Stress concentration factor for the 
different radius of curvature

\subsection{Stress Simulation of Interpolation lines with variable length}

The radius of curvature is $3000 \mathrm{~mm}$, the maximum stress and the average stress under different central angles and the length of interpolated lines are shown in Fig 12. When the curvature is kept constant, the stress concentration factor for changing the length of the interpolation straight lines is shown in Fig 13.

When the central angle and curvature are kept constant, the maximum stress decreases as the length of interpolation lines increases. However, when the central angle is too large, the reduction trend of the maximum stress is not obvious. As shown in Fig 12. When the radius of curvature and length of the interpolation lines are kept constant, the stress concentration factor decreases as the central angle increases. When the central angle and curvature are kept in constant, the stress concentration factor increases with the increase of the length of the interpolation lines. As shown in Fig 13.

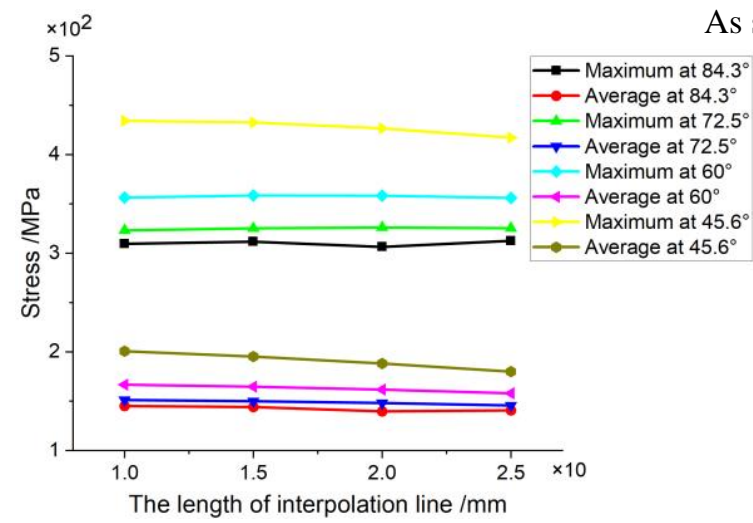

Fig. 12. Maximum stress and average stress of different interpolation lines lengths

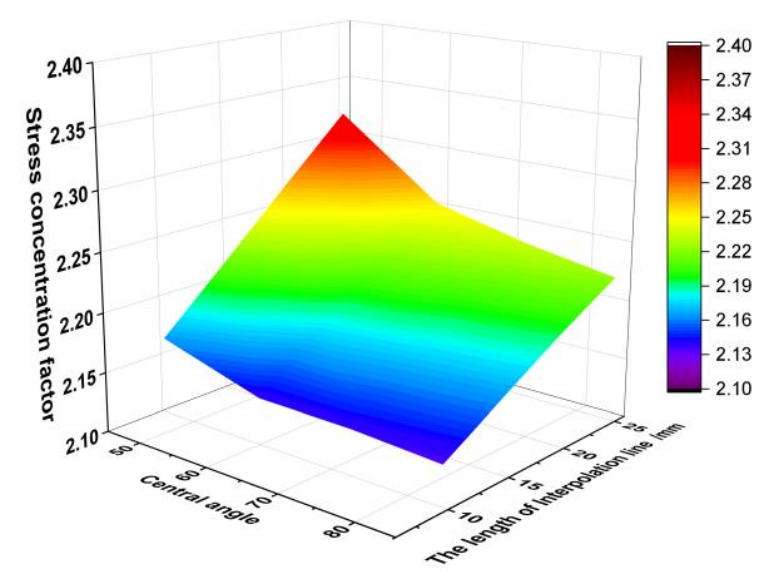

Fig. 13. Stress concentration factor of different interpolation straight lines length

\section{Discussion}

\subsection{Maximum stress and average stress}

When the central angle is kept constant, changing the curvature and the length of interpolation lines will result in changes in the stress concentration. The greater the stress concentration factor, the smaller the maximum stress, which is significant at the central angle of $45.6^{\circ}$. To study the reasons, we assumed the processed surfaces as a smooth flat plate structure.

As shown in Fig 14.

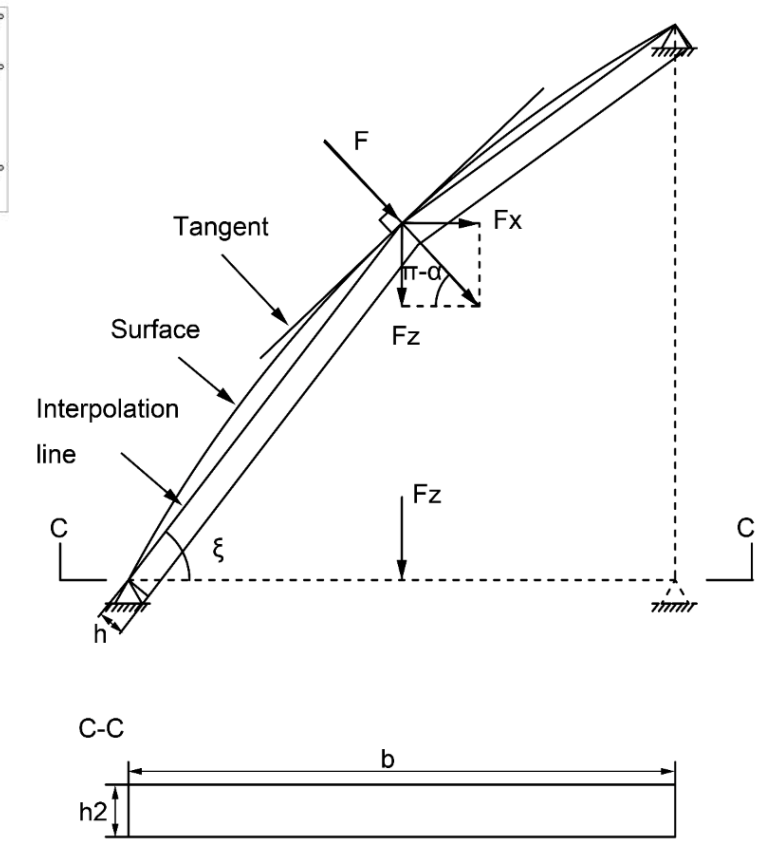

Fig. 14. Interpolate the pressure at the connection point of the straight lines

Decompose the force into $F_{x}$ and $F_{z}$, and convert it into lateral bending. Solve the 
maximum normal stress according to the formula: $\sigma_{1}=M_{\max } / W . M_{\max }$ is the maximum bending moment. $M_{\max }=1 / 2 \times F_{z} \times b . W$ is the bending section coefficient. When the cross-section is rectangular. $W=\left(b \times h^{2}\right) / 6 . b$ is the width of the section. $h$ is the height of the section.

$\sigma_{1}=\left(3 \times F_{\mathrm{z}}\right) / h_{2}^{2}=(3 \times F \times \sin (\pi-\alpha)) /\left(h^{2} \times(\cos \xi)^{2}\right)$

. Because $F$ and $h$ are kept constant, the numerical of $\sigma_{l}$ is related to $\sin (\pi-\alpha) /(\cos \xi)^{2} . F$ is $1 \mathrm{~N}, h$ is $0.01 \mathrm{~mm}$, solve the $\sigma_{l}$. As shown in Fig 15 and Fig 16. $\sigma_{1}$ increases as the radius of curvature increases, and decreases as the length of interpolation lines increases. Because the simulated surfaces are in the shape of small pits. With the increase of $\xi$, the error in a numerical value is larger.

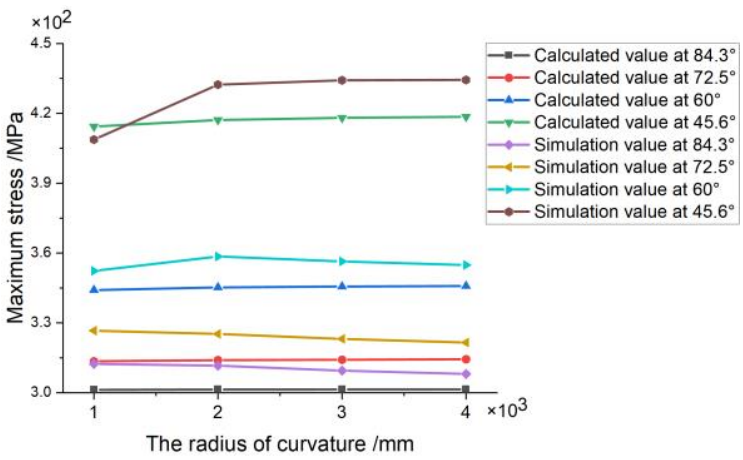

Fig. 15. Stress simulation and calculation values for the different radius of curvature

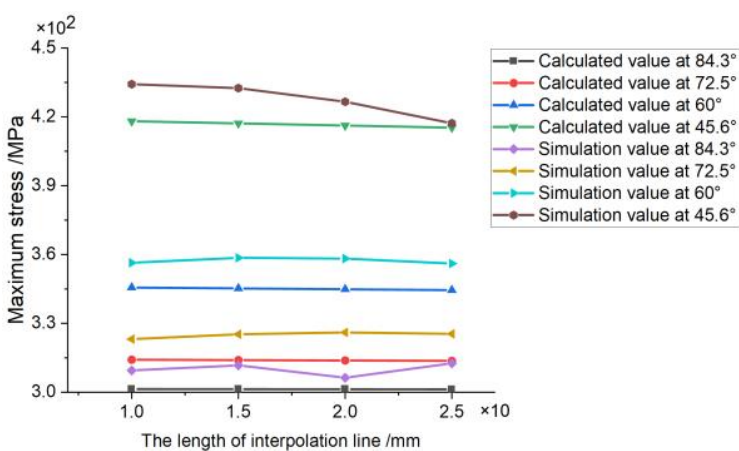

Fig. 16. Stress simulation and calculation values of different interpolation lines lengths

4.2 Relationship between sharp angle and stress concentration factor
When fitting a curved surface with interpolation lines, sharp corners will be formed at the joint of the interpolation lines. As shown in Fig 17. Use E/F to indicate the angle at which the interpolation straight lines form a sharp corner. When E/F is larger, the angle at the joint of the interpolation lines is smaller.

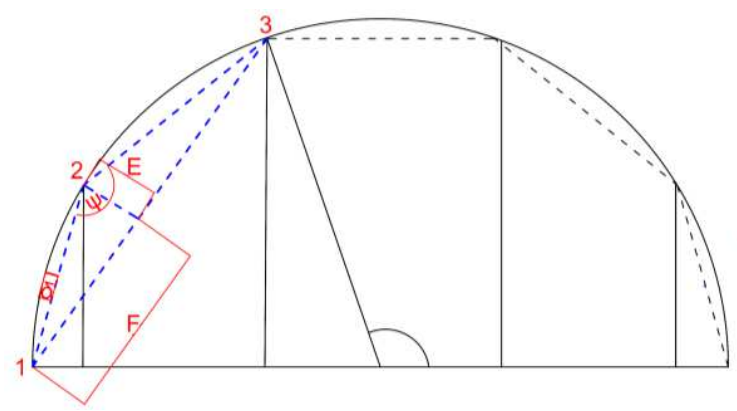

Fig. 17. The angle formed by adjacent interpolated lines

Solve the values of $\mathrm{E} / \mathrm{F}$ under different curvatures, the length of interpolation lines, and center angles. The stress concentration factor is linearly related to $\mathrm{E} / \mathrm{F}$. As shown in Fig 18 . The greater the value of $\mathrm{E} / \mathrm{F}$, the greater the stress concentration factor

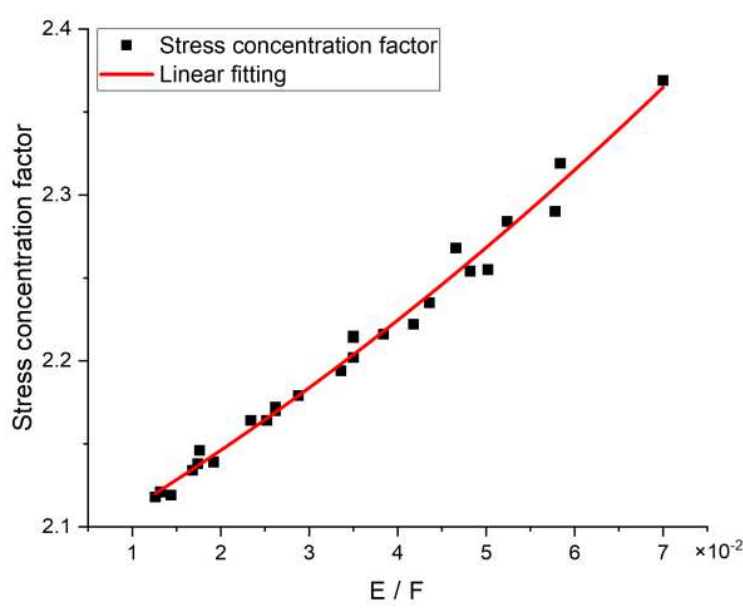

Fig. 18. The sharpness of included angle and stress concentration factor

\subsection{Relationship between machining error} and stress concentration factor

When fitting a curved surface with interpolation lines, the machining error $\delta$ is unavoidable. According to the formula: $\delta_{i}=\left|A_{i} X_{i}+B_{i} Z_{i}+C_{i}\right| / \sqrt{A^{2}+B^{2}}$, the machining $\delta$ under different curvatures, the length of 
interpolated line, and center angles can be obtained. $A_{i} X_{i}+B_{i} X_{i}+C_{i}=0$ is the equation of each interpolation lines. $\left(X_{i}, Z_{i}\right)$ is the coordinate point on the curved surfaces corresponding to the intermediate point of each interpolation line. As is shown in Fig 19. In processing, the error is generally within $0.03 \mathrm{~mm}$. In Figure 19, the stress concentration factor within $0.03 \mathrm{~mm}$ ranges from 2.1 to 2.4. Most of the stress concentration factors are within 2.1 to 2.23. Most of the stress concentration formed at the small radius of curvature and small central angle exceeds 2.23. The smaller the stress concentration factor, the better the surface's integrity. To ensure the overall performance, the stress concentration factors of each part should be made to be similar. In some parts, it is necessary to reduce the stress concentration factor by reducing the length of the interpolation lines.

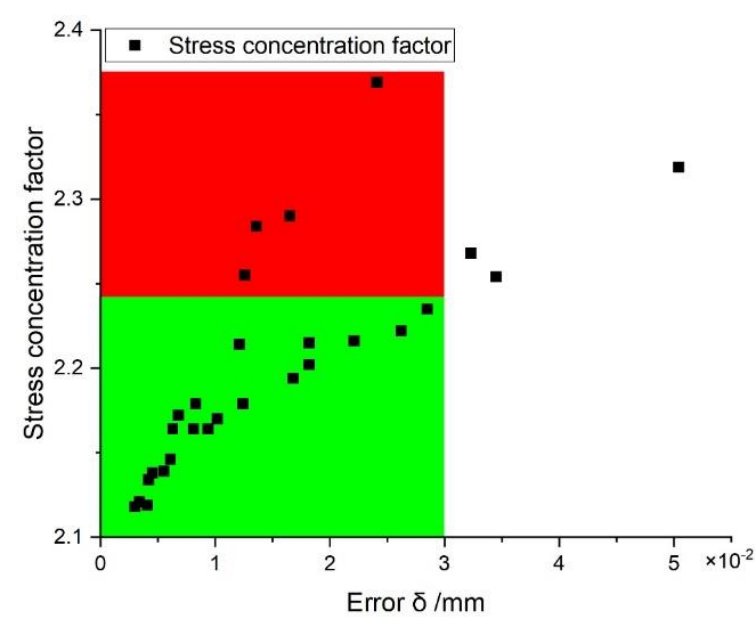

Fig. 19. Machining error and stress concentration factor
Of course, the residual height formed in the step direction also affects the stress concentration. Tabriz and Barrans[20] Conducted related research. The diameter of the ball-end milling cutter used in this article is $25 \mathrm{~mm}$ and the step distance is $0.5 \mathrm{~mm}$. The residual height is about $0.00125 \mathrm{~mm}$. Because the residual height is too small, it has been ignored in this article.

\subsection{Selection of Interpolation Lines Length Based on Stress Concentration}

Based on the above research, a method for selecting the length of the interpolation lines when fitting a curved surface is proposed. First, according to the curvature and tolerance, the maximum interpolation straight line length is solved according to the formula $L_{\max }=2 \sqrt{2 R \delta}$. This article regards the chord length as the length of the bisecting curve. This will cause the error in some parts to exceed the set value. When the error exceeds the set value, the dichotomy method is used to reduce the length of interpolation lines. Finally, when the error satisfies the set value, the stress concentration factor of some parts is too large, and it needs to be further adjusted by dichotomy. When the stress concentration factor decreases, the maximum stress will increase. By ensuring that the maximum stress is lower than the allowable stress, the minimum length of the interpolation lines can be determined. As shown in Fig 20. 


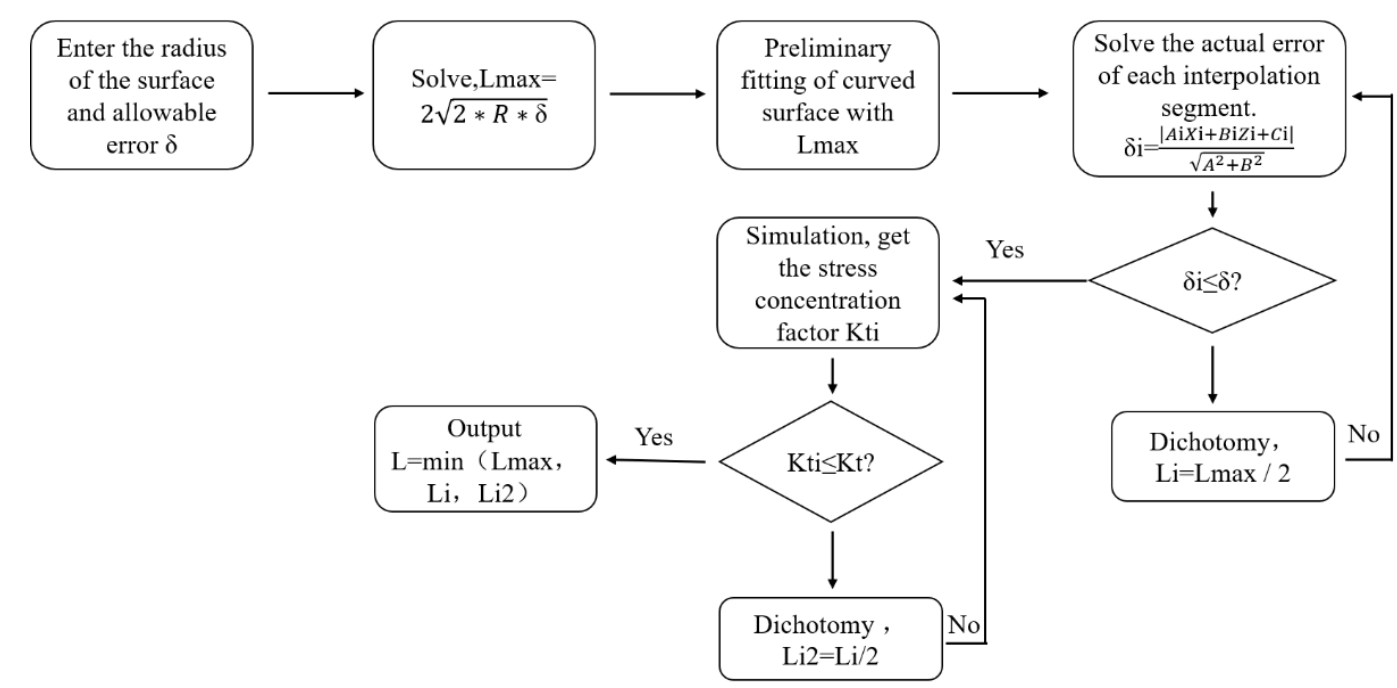

Fig. 20. Selection of the length of the interpolation lines

\section{Conclusion}

Surface topography model and surfaces stress simulation of ball-end milling surfaces controlled by acceleration and deceleration. Reveals the relationship between the three variables of the length of interpolation lines, the radius of curvature, and the angle of the center angle, and the stress concentration factor. Realize the optimization of the length of interpolation lines through the radius of curvature, the angle of the central angle, and the stress concentration factor. The conclusions of this study are as follows:

(1) When the length of the interpolation lines and the central angle are kept constant, the maximum value of stress increases with the increase of radius of curvature, and the stress concentration factor decreases with the increase of radius of curvature. When the central angle is $45.6^{\circ}$ and the length of the interpolation lines is $10 \mathrm{~mm}$. The maximum stresses with the radius of curvature of $2000 \mathrm{~mm}, 3000 \mathrm{~mm}$, and $4000 \mathrm{~mm}$ are increased by $5.8 \%, 6.2 \%$, and $6.3 \%$ respectively relative to the maximum stresses with the radius of curvature of $1000 \mathrm{~mm}$, and the stress concentration factors were reduced by $7.6 \%$, $9.7 \%$, and $10.4 \%$ respectively.

(2) When the radius of curvature and the central angle is kept constant, the maximum stress decreases with the increase of the length of the interpolation lines, and the stress concentration factor increases with the increase of the length of the interpolation lines. When the central angle is $45.6^{\circ}$ and the radius of curvature is $3000 \mathrm{~mm}$. The maximum stress of the interpolation lines length of $15 \mathrm{~mm}, 20 \mathrm{~mm}$, and $25 \mathrm{~mm}$ is reduced by $0.4 \%, 1.8 \%$, and $3.9 \%$, respectively, compared with the maximum stress of the interpolation lines length of $10 \mathrm{~mm}$, and the stress concentration factors increased by $2.36 \%$, $4.81 \%$, and $7.16 \%$ respectively.

(3) When the radius of curvature and the length of the interpolation straight lines are kept constant, the maximum stress increases with the decrease of the central angle, and the stress concentration factor increases as the central angle decreases. When the radius of curvature is $1000 \mathrm{~mm}$ and the length of the interpolation lines is $10 \mathrm{~mm}$. The maximum stresses with a central angle of $72.5^{\circ}, 60^{\circ}$, and $45.6^{\circ}$ are increased by $4.6 \%, 12.8 \%$, and $30.8 \%$, respectively, compared to the maximum stress with a central angle of $84.3^{\circ}$, and the stress concentration factors increased by $1.3 \%, 1.6 \%$, and $6.3 \%$ respectively.

(4) The sharp angle formed by the stress concentration factor and the interpolation line shows a positive correlation trend. To reduce the stress concentration on the machined surface, it 
can be solved by controlling the length of the interpolation line to reduce the sharp angle formed by the interpolation line.

Author contributions Hang Li developed the idea, implemented the code, and wrote the paper. Peirong Zhang came up the idea. Peirong Zhang, Guosheng $\mathrm{Su}$, Jin $\mathrm{Du}$, and Chonghai $\mathrm{Xu}$ discussed and commented in the article. Guosheng Su secured the funding.

Funding This research was supported by the National Natural Science Foundation of China (52075275), Key Research and Development Plan of Shandong Province (2018GGX103023), Innovation Team Project of Colleges and Institutions in Jinan City (2018GXRC005).

Availability of data and materials There are no additional data and materials.

Code availability Software application

\section{Declarations}

Consent for publication The authors declare that they all consent to publication.

Conflict of interest The authors declare that they have no conflict of interest.

Ethics approval and consent to participate N/A

Open Access This article is licensed under a Creative Commons Attribution 4.0 International License, which permits use, sharing, adaptation, distribution and reproduction in any medium or format, as long as you give appropriate credit to the original author(s) and the source, provide a link to the Creative Commons licence, and indicate if changes were made. The images or other third party material in this article are included in the article's Creative Commons licence, unless indicated otherwise in a credit line to the material. If material is not included in the article's Creative Commons licence and your intended use is not permitted by statutory regulation or exceeds the permitted use, you will need to obtain permission directly from the copyright holder. To view a copy of this licence, visit

http://creativecommons.org/licenses/by/4.0/.

\section{References}

1. Rao VS, Rao PVM (2005) Modelling of tooth trajectory and process geometry in peripheral milling of curved surfaces. International Journal of Machine Tools and Manufacture 45(6):617-630.

https://doi.org/10.1016/j.ijmachtools.2004. 10.004

2. Wei ZC, Wang MJ, Ma RG, Wang L (2010) Modeling of process geometry in peripheral milling of curved surfaces. Journal of Materials Processing Technology 210(5): 799-806.

https://doi.org/10.1016/i.jmatprotec.2010.0 1.011

3. Zhang PR, Liu ZQ (2016) Modeling and prediction for 3D surface topography in finish turning with conventional and wiper inserts. Measurement 94:37-45. https://doi.org/10.1016/j.measurement.2016 .07 .080

4. Mohammad M, Mohammad MR (2019) An analytical model for cutter-workpiece engagement calculation in ball-end finish milling of doubly curved surfaces. International Journal of Advanced Manufacturing Technology 102:1635-1657. https://doi.org/10.1007/s00170-018-3188-y

5. Li SJ, Dong YH, Li Y, Li PY, Yang ZC, Robert GL (2019) Geometrical simulation and analysis of ball-end milling surface topography. International Journal of Advanced Manufacturing Technology 102:1885-1900.

https://doi.org/10.1007/s00170-018-03217$\underline{5}$

6. Dhokia VG, Kumar S, Vichare P, Newman, ST (2008) An intelligent approach for the prediction of surface roughness in ball-end machining of polypropylene. Robotics and 
Computer Integrated Manufacturing 24(6):835-842.

https://doi.org/10.1016/j.rcim.2008.03.019

7. Quinsat Y, Lavernhe S, Lartiguea C (2011) Characterization of 3D surface topography in 5-axis milling. Wear 271(3-4):590-595. https://doi.org/10.1016/j.wear.2010.05.014

8. Vyboishchik AV. (2016) Modelling topology of freeform surfaces with ball-end milling. Procedia Engineering 150: 761-767.

https://doi.org/10.1016/j.proeng.2016.07.10 $\underline{3}$

9. Xu JT, Zhang H, Sun YW (2018) Swept surface-based approach to simulating surface topography in ball-end CNC milling. The International Journal of Advanced Manufacturing Technology 98: 107-118.

https://doi.org/10.1007/s00170-017-0322-1

10. Vu DD, Monies F, Rubio W, Fratini L, Di Lorenzo R, Buffa G, Ingarao G (2018) A new optimization tool path planning for 3 -axis end milling of free-form surfaces based on efficient machining intervals. AIP Conference Proceedings 1960:070011. https://doi.org/10.1063/1.5034907

11. Lotfi S, Wassila B, Gilles D (2018) Cutter workpiece engagement region and surface topography prediction in five-axis ball-end milling. Machining Science \& Technology 22:181-202.

https://doi.org/10.1080/10910344.2017.133 $\underline{7131}$

12. Arizmendi M, Jiménez A (2019) Modelling and analysis of surface topography generated in face milling operations. International Journal of Mechanical Sciences 163:105061. https://doi.org/10.1016/j.ijmecsci.2019.105 061

13. Torta M, Albertelli P, Monno M (2020) Surface morphology prediction model for milling operations. International Journal of
Advanced Manufacturing Technology 106: 3189-3201.

https://doi.org/10.1007/s00170-019-04687-

14. Cai CY, An QL, Ming WW, Chen M (2021) Modelling of machined surface topography and anisotropic texture direction considering stochastic tool grinding error and wear in peripheral milling. Journal of Materials Processing Technology 292:117065.

https://doi.org/10.1016/j.jmatprotec.2021.1 17065

15. Zhou RH, Yang WY (2019) Analytical modeling of machining-induced residual stresses in milling of complex surface. The International Journal of Advanced Manufacturing Technology 105:565-577. https://doi.org/10.1007/s00170-019-042197

16. Urbikain G, Lopez de Lacalle LN (2018) Modelling of surface roughness in inclined milling operations with circle-segment end mills. Simulation Modelling Practice and Theory 84:161-176. https://doi.org/10.1016/j.simpat.2018.02.00 $\underline{3}$

17. Zeng HH, Yan R, Du PL, Zhang MK, Peng FY (2018) Notch wear prediction model in high speed milling of AerMet100 steel with bull-nose tool considering the influence of stress concentration. Wear 408-409:228-237 https://doi.org/10.1016/j.wear.2018.05.024

18. Yang SC, Yu S, He CS (2019) The Surface Integrity of Titanium Alloy When Using Micro-Textured Ball-End Milling Cutters. Micromachines 10(1):21. https://doi.org/10.3390/mi10010021

19. Zhou RH, Yang WY (2019) Analytical modeling of machining-induced residual stresses in milling of complex surface. The International Journal of Advanced Manufacturing Technology 105:565-577. 
https://doi.org/10.1007/s00170-019-042197

20. Li YE, Zhang HH, Zhao J (2017) A study of machined surface RS gradient distribution and cumulative on HSM ball end milling. International Journal of Advanced Manufacturing Technology 91(1-4):1431-1442.

https://doi.org/10.1007/s00170-016-9712-z

21. Jaime Tupiassú Pinho DC, Daniel DAS, Ivan Fabio Mota DM, Marco Antonio M (2016) A note on notch shape optimization to minimize stress concentration effects. Theoretical and Applied Fracture Mechanics 84:72-85. https://doi.org/10.1016/j.tafmec.2016.03.00 $\underline{5}$

22. Tabriz MSE, Barrans S (2018) Effect of machining cusps on the stress concentration factor on curved surface. International Journal of Mechanical Engineering and Robotics Research 7(5):552-557. https://doi.org/10.18178/ijmerr.7.5.552-557

23. Felhőa C, Karpuschewskib B, Kundráka J. (2015) Surface Roughness Modelling in Face Milling. 15Th Cirp Conference on Modelling of Machining Operations (15TH CMMO) 31:136-141. https://doi.org/10.1016/j.procir.2015.03.075

24. Chen G, Zou YH, Qin XD, Liu J, Feng Q, Ren CZ (2020) Geometrical texture and surface integrity in helical milling and ultrasonic vibration helical milling of Ti-6Al-4V alloy. Journal of Materials Processing Technology 278:116494. https://doi.org/10.1016/j.jmatprotec.2019.1 $\underline{16494}$ 